\title{
Lung Cancer Prevalence in Hill Region of Nepal
}

\author{
Pramod Bhatta ${ }^{1}$, Bhakta Man Shrestha ${ }^{2}$
}

${ }^{1}$ PhD Scholar, Mewar University, Rajasthan, India, bhattapra@ gmail.com

${ }^{2}$ Executive Chairman, NPL, Bharatpur, Chitwan

\section{ABSTRACT}

Nepal being one of the low and middle income countries where disease pattern shifted from communicable to non communicable diseases such as heart and cancer diseases since past. Primary focus of the study was to explore the prevalence of lung cancer in Hill region of Nepal. The study survey was conducted in BP Koirala Memorial Cancer Hospital, Bharatpur Chitwan. The study applied quantitative research design. The data was collected from the records of 800 cancer diagnosed patients of the hospital. The record was collected and analyzed from 160 randomly selected cancer cases from year 2009 to 2013. The study was non experimental, descriptive, exploratory and cross-sectional research design. Findings suggested that lung cancer cases were high 32.9\% in Hill region. Smoking habit was also found in $56.1 \%$ patients, the findings suggested that the reason of high lung cancer might be attributable to high smoking prevalence. High lung cancer prevalence found in Hill region of Nepal which signifies the need of further investigation on lung cancer and related risks in these areas.

\section{KEYWORDS}

Hill, Lung cancer, Prevalence, Smoking

\section{INTRODUCTION}

There were 14.1 million new cancer cases, 8.2 million cancer deaths and 32.6 million people living with cancer (within 5 years of diagnosis) in 2012 worldwide. 57\% (8 million) of new 
cancer cases, 65\% (5.3 million) of the cancer deaths and 48\% (15.6 million) of the 5-year prevalent cancer cases occurred in the less developed regions of the world. Nepal also belongs among the low and middle income (LMIC) countries. In most of these areas, lung cancer is the leading contributor to cancer deaths accounting for an estimated 1.59 million deaths (Raspanti, 2016). The study findings suggested that there was shift of disease pattern since past to recent days in the country from communicable to non communicable diseases (Baral, 2015). Previous literatures also indicated that there is no exact data available lung cancer in the country which could actually reflect the lung cancer problem in Nepal (Joshi, 2003)

In Nepal lung cancer was found most common malignancy in males and third most common malignancy in females similarly the country had highest percentage of smokers with males accounting for $48 \%$. Tobacco use, especially cigarette smoking, accounts for up to $90 \%$ of all lung cancer deaths worldwide (Chawla, Sathian, Mehra, Kiyawat, Garg, \& Sharma, 2010). No exact data on cancer prevalence available in Nepal but based on hospital records it was estimated that incidence from the report of cancer hospital 2012 showed 100 to 120 cancer patients per 100,000 population in Nepal (B P Koirala Memorial Cancer Hospital, 2012). The associated risk factors for lung cancer worldwide found to be cigarette smoking.

The major cancer types found in Nepal based on the hospital reports were lungs, oral, gastric and colon.

The objective of the study was to explore lung cancer prevalence in Hill region of Nepal.

Review of lung cancer in South Asian countries reviled that Nepal lung cancer mortality was high 6000 per 100000 patients from WHO report 2014 country profile (World Health Organization, 2014). The study was to explore the lung cancer status in Hill region and habit 
smoking as its risk factor. The use of tobacco as smoking found to be associated with lung cancer which was evident from several studies which showed the association of tobacco smoking as the major risk factor in developing lung cancer (Subedi \& Sharma, 2013). The people of Hill region of Nepal mostly had habit of cigarette smoking which might show the higher percent of lung cancer.

\section{MATERIALS AND METHODS}

The study was conducted on the basis of hospital recorded data. Total 800 data was collected from the hospital record of diagnosed cancer patients. The simple random sampling technique was applied to collect 160 cancer diagnosed cancer cases each year from year 2009 to 2013 using the checklist to collect the information on lung cancer retrieved from the hospital at B P Koirala Memorial Cancer Hospital, Bharatpur, Chitwan. Quantitative research method was applied in the study. The study was non-experimental, descriptive, exploratory and cross sectional research design. The data was then analyzed for frequency and cross tabulation to describe the findings. The region of Nepal was divided based on Chure Hill range. North to this range considered as Hill for the study purpose.

\section{RESULTS AND DISCUSSION}

Most of the cancer patients from Hill regions were from age group 41 to 60 years. Majority of the patients and most of them were farmers. The people had less access to the health services. The total number of cancer patients from Hill region were $47.13 \%$ most of them were from Janajati (Ethnic group) 34.6\% . Around 90\% patients were Hindu followed by Buddhist and other religion. 
The results of analysis on lung cancer in Hill showed the following:

Table 1: Gender based cancer case distribution in Hill region of Nepal.

\begin{tabular}{|l|c|c|}
\hline \multirow{2}{*}{ Region } & \multicolumn{2}{|c|}{ Sex } \\
\cline { 2 - 3 } & Female (\%) & Male (\%) \\
\hline Hill & 43.2 & 56.8 \\
\hline
\end{tabular}

Source: Field survey, 2015

There were $43.2 \%$ female $56.8 \%$ male cancer patients in the hill region (Table 1). The above data showed the distribution of male and female cancer patients differ slightly. High smoking prevalence, indoor smoke etc. found associated with lung cancer which was also found from the above table. In the article Pradhan et al. mentioned that since 1987, more women have died each year of lung cancer than of the breast cancer (Pradhan, Shakya, \& Shrestha, 2014).

\section{Table 2: Age group of cancer patients.}

\begin{tabular}{|l|c|}
\hline Age group & Percent (\%) \\
\hline 21 to 40 & 18.2 \\
\hline 41 to 60 & 48.3 \\
\hline 61 and above & 33.5 \\
\hline
\end{tabular}

Source: Field Survey, 2015 
There were $18.2 \%$ cancer patients of age group 21 to 40 years and that from age group 41 to 60 years were $48.3 \%$, similarly the age group of 61 and above $33.5 \%$ from survey data of cancer patients. From the above Table 2 the highest age group who developed cancer were 41 to 60 years followed by the group 61 years and above. The findings suggested that the age of patients was above 40 who developed cancer.

\section{Lung Cancer case Distribution based on region of Nepal}

Table 3: Distribution of lung cancer and other cancers patients based on Hill region.

\begin{tabular}{|l|c|c|}
\hline Region & Lung (\%) & Other cancers (\%) \\
\hline Hill & 32.9 & 67.1 \\
\hline
\end{tabular}

Source: Field Survey, 2015

The record data showed that lung cancer cases were $32.9 \%$ whereas other cancers (oral, breast cancer cervix/ uterus colon and colorectal, liver, pancreas, gall bladder stomach cancer blood, lymphoma, penis, skin etc.) $67.1 \%$ in the Hill region (Table 3). In the study of Poudel et al. also showed that lung and bronchus cancer had the highest incidence (4.45) in Nepal (Poudel, Huang, \& Neupane, 2016). Lung cancers were found almost one third among the cancer patients.

The findings of data analysis showed that there were $56.1 \%$ patients were smokers with cancers from hospital records in Hill region of Nepal. Increased number of lung cancer could be due to the increasing trend of smoking habit among the women. Smokers account to $80-90 \%$ of the lung cancer cases where as non smoker accounts to about 10-15\% of cases (Pradhan, Shakya, \& Shrestha, 2014), (Subedi K. S., 2013). These risk factors were explored on the basis of geographical distribution, age, and sex. The analytical comparison of lungs and other cancers based on 
geographical distribution showed that there were more lungs cancer cases in Hill region from the data. Study findings of Subedi and Sharma also showed due to the high prevalence of tobacco smoking, lung cancer is the commonest in both genders in Nepal (Subedi \& Sharma, 2012)

The above findings showed that cancer prevalence was more in Hilly region of Nepal. The smoking prevalence was high in hilly region too. Therefore, a comprehensive approach to raise the awareness highlighting the risk factors among them becomes essential to control and promote cessation of tobacco use among current users to prevent them from tobacco related diseases.

\section{CONCLUSIONS}

There are more lung cancer cases in Hill region of Nepal. The study findings suggest that high tobacco smoking might have played role in increasing lung cancer case. The finding on high lung cancer prevalence warrants that there is need to explore and implement effective lung cancer prevention and care programs.

\section{ACKNOWLEDGEMENTS}

I would like to thank Dr. Bhakta Man Shrestha, Dr. Tej Bahadur Karki, and Dr.Bidur Dhungel for their kind support. 


\section{AUTHOR 2}

Developed the idea, reviewed and corrected the manuscript.

\section{ETHICAL APPROVAL}

Ethical approval was taken from Nepal Health Research Council, Ram Shah path,

Kathmandu Nepal.

\section{REFERENCES}

B P Koirala Memorial Cancer Hospital. (2012). Annual Report. Chitwan, Nepal: BPKMCH.

Baral, G. (2015). Right Shift of Disease Pattern. J Nepal Health Res Council , 1-2.

Chawla, R., Sathian, B., Mehra, A., Kiyawat, V., Garg, A., \& Sharma, K. (2010). Awareness and Assessment of Risk Factors for Lung Cancer in Residents of Pokhara Valley. Asian Pacific J Cancer Prev, 1789-1793.

Joshi, S. K. (2003). Occupational cancer in Nepal - an update. Kathmandu University Medical Journal , 144-151.

Poudel, K. K., Huang, Z., \& Neupane, P. R. (2016). Age specific incidence of five major cancers in Nepal, 2012. Nepal Journal of Epidemiology, 565-573.

Pradhan, S., Shakya, S., \& Shrestha, S. (2014). Clinico-Pathological Study of Lung Carcinoma. Journal of Pathology of Nepal , 623.

Raspanti, G. A. (2016). Lung cancer in nepal: the role of traditional tobacco products and combustion related household air pollution. University of Maryland.

Subedi, K. S. (2013). Tobacco-attributed Cancer Incidence is Rising in Nepal Due to Increasing Prevalence of Tobacco Use: A Major Challenging Burden for Nepal. Austral - Asian Journal of Cancer, 89-95.

Subedi, K. S., \& Sharma, P. (2012). Cancer Treatment in Nepal: A Historical Background, Development of Treatment Facilities, Epidemiology and Challenges for Prevention and Control of Cancer. Austral - Asian Journal of Cancer , 205-212.

World Health Organization. (2014). Cancer Country Profile Nepal. WHO. 